\title{
Intraoperative infusion of lidocaine reduces postoperative fentanyl requirements in patients undergoing laparoscopic cholecystectomy
}

\author{
[Une perfusion peropératoire de lidocaïne réduit les besoins postopératoires en \\ fentanyl chez les patients subissant une cholécystectomie par laparoscopie]
}

Severine Lauwick MD, ${ }^{*}$ Do Jun Kim Msc, ${ }^{*}$ Giuliano Michelagnoli MD, ${ }^{*}$ Giovanni Mistraletti MD, ${ }^{*}$ Liane Feldman MD, $\dagger$ Gerald Fried MD, $†$ Franco Carli MD MPHIL*

Background: Lidocaine has been shown to inhibit neural conduction and to have anti-inflammatory properties. The purpose of this study was to determine whether intraoperative lidocaine infusion reduces opioid consumption in the postanesthesia care unit (PACU).

Methods: Fifty patients were enrolled in this prospective, randomized and observer-blinded study. At induction of anesthesia the control group $(n=25)$ received fentanyl $3 \mu \mathrm{g} \cdot \mathrm{kg}^{-1}$ while the lidocaine group received fentanyl $1.5 \mu \mathrm{g} \cdot \mathrm{kg}^{-1}$ and a bolus of lidocaine $1.5 \mathrm{mg} \cdot \mathrm{kg}^{-1}$ followed by a continuous infusion of lidocaine $2 \mathrm{mg} \cdot \mathrm{kg}^{-1} \cdot \mathrm{hr}^{-1}$. General anesthesia included propofol, rocuronium, and desflurane titrated to maintain blood pressure and heart rate within set parameters, and the bispectral index between 35 and 50 . No supplemental opioids were given during surgery. All patients received acetaminophen, ketorolac, dexamethasone, droperidol and local anesthetics in the skin incision. Patients received fentanyl and ondansetron in the PACU. The primary outcome variable was the amount of fentanyl required in the PACU to establish and to maintain visual analogue scale pain scores $<3$.

Results: Most patients received fentanyl for pain relief in the PACU, but the cumulative mean dose was lower in the lidocaine group compared to the control group (98 $\pm 54 \mu \mathrm{g}$, vs $154 \pm$ $99 \mu \mathrm{g}$, respectively, $P=0.018)$. Lidocaine infusion reduced by $10 \%$ the amount of desflurane required $(P=0.012)$. White-Song scores $>12$ were attained by all patients in both groups within 30 min of their arrival in the PACU. Median time from arrival to the PACU to discharge home was similar in both groups, $167.5 \mathrm{~min}$ in the control group vs $180 \mathrm{~min}$ in the lidocaine group $(P=0.649)$.

Conclusion: Intraoperative lidocaine infusion reduces opioid consumption in the PACU and intraoperative requirements of desflurane.

CAN J ANESTH $2008 / 55: 11 /$ pp 754-760

Contexte : Il a été démontré que la lidocaïne inhibe la conduction nerveuse et possède des propriétés anti-inflammatoires. L'objectif de cette étude était de déterminer si une perfusion peropératoire de lidocaïne réduisait la consommation d'opioïdes dans la salle de réveil.

Méthode : Cinquante patients ont été recrutés dans le cadre de cette étude prospective, randomisée et à double insu. Lors de l'induction de l'anesthésie, le groupe témoin $(n=25)$ a reçu $3 \mu \mathrm{g} \cdot \mathrm{kg}^{-1}$ de fentanyl, et le groupe lidocaïne a reçu $1,5 \mu \mathrm{g} \cdot \mathrm{kg}^{-1}$ de fentanyl ainsi qu'un bolus de $I, 5 \mathrm{mg} \cdot \mathrm{kg}^{-1}$ de lidocaïne suivi d'une perfusion continue de $2 \mathrm{mg} \cdot \mathrm{kg}^{-1} \cdot \mathrm{hr}^{-1}$ de lidocaïne. L'anesthésie générale était composée de propofol, de rocuronium et de desflurane titré afin de maintenir la pression artérielle et la fréquence cardiaque dans la limite de paramètres préétablis, et l'index bispectral entre 35 et 50 . Aucun opioïde supplémentaire n'a été administré pendant la chirur-

From the Department of Anesthesia, ${ }^{*}$ and the Department of Surgery and Steinberg-Bernstein Centre for Minimally Invasive Surgery, $\dagger$ McGill University Health Centre; Montreal, Quebec, Canada.

Address correspondence to: Dr. Franco Carli, Department of Anesthesia, McGill University Health Centre, 1650 Cedar Avenue, Room D10.144, Montreal, Quebec H3G 1A4, Canada. E-mail: franco.carli@mcgill.ca

Dr S. Lauwick was awarded a clinical fellowship from the Steinberg-Bernstein Centre for Minimally Invasive Surgery and the Montreal General Hospital Foundation, and a clinical research grant from the CHU of LIEGE, Belgium. Dr. G. Michelagnoli received a research fellowship from the Department of Anesthesia, University of Florence, Italy. Dr. G. Mistraletti was supported by the Istituto di Anestesiologia e Rianimazione, University of Milan, San Paolo Hospital, Milan, Italy.

This work was supported by internal funds, Department of Anesthesia, McGill University Health Centre.

None of the authors has any conflict of interest related to this study.

Accepted for publication July 21, 2008.

Revision accepted August 28, 2008. 
gie. Tous les patients ont reçu de l'acétaminophène, du kétorolac, de la dexaméthasone, du dropéridol et des agents anesthésiques locaux au niveau de l'incision cutanée. Les patients ont reçu du fentanyl et de l'ondansétron en salle de réveil. Le critère d'efficacité principal était la quantité de fentanyl nécessaire en salle de réveil pour établir et maintenir des scores de douleur $<3$ sur une échelle visuelle analogique.

Résultats : La plupart des patients ont reçu du fentanyl en salle de réveil pour soulager la douleur, mais la dose moyenne cumulative était plus basse dans le groupe lidocaïne que dans le groupe témoin (98 $\pm 54 \mu \mathrm{g}$, vs $154 \pm 99 \mu \mathrm{g}$, respectivement, $P=0,018$ ). La perfusion de lidocaïne a réduit la quantité de desflurane requise de $10 \%(P=0.012)$. Des scores de White-Song $>12$ ont été obtenus chez tous les patients dans les deux groupes au cours des 30 premières minutes après leur transfer $t$ à la salle de réveil. Le temps médian entre l'arrivée en salle de réveil et le congé de l'hôpital était semblable dans les deux groupes, soit 167,5 min dans le groupe témoin vs 180 min dans le groupe lidocaïne $(P=0,649)$.

Conclusion: Une perfusion peropératoire de lidocaïne réduit la consommation d'opiacés en salle de réveil et les besoins peropératoires de desflurane.

I NTRAOPERATIVE analgesia is traditionally provided by opioid analgesics. However, the use of opioids during ambulatory surgery can be associated with an increased incidence of postoperative complications, such as respiratory depression, sedation, postoperative nausea and vomiting (PONV), ileus, and urinary retention. ${ }^{1}$ Some of these side effects can delay recovery and discharge from the day-surgery unit, and can cause unanticipated hospital admission. ${ }^{2}$ It is therefore appropriate to minimize these side effects by using either multimodal analgesic techniques or adjuvant therapies to reduce the doses of opioids.

The fact that pain after laparoscopic cholecystectomy is complex in nature, and has unique elements compared to other laparoscopic procedures, suggests that effective analgesic treatment must be multimodal in nature. ${ }^{3}$ Bisgaards et al. ${ }^{4}$ suggested a prophylactic multimodal analgesia regimen to reduce postoperative pain, consisting of intraoperative short-acting opioids, injection of local anesthetics into the surgical wound, nonsteroidal anti-inflammatory drugs and dexamethasone. In spite of this multipharmacological intervention, postoperative analgesia has not been consistently satisfactory. ${ }^{2}$

Intravenous lidocaine has been shown to provide good pain relief in patients who underwent retropubic prostatectomy ${ }^{5}$ and laparoscopic colon resection. ${ }^{6}$ This effect appears to be due to a reduction of neural responses to pain by inhibiting nerve conduction. ${ }^{7}$ In addition, lidocaine has significant anti-inflammatory properties. ${ }^{8} \mathrm{Wu}$ et al. ${ }^{9}$ administered a lidocaine infusion in patients undergoing laparoscopic cholecystectomy and reported a meperidine-sparing effect during the postoperative period, however the intervention did not include multimodal analgesia. In addition, the study did not report on side effects in the postanesthesia care unit (PACU), and hospital discharge readiness times.

The present prospective, randomized controlled trial was designed to analyze the effect of intraoperative infusion of lidocaine, on postoperative opioid requirements, and the incidence of side effects and readiness for hospital discharge. We hypothesized that patients receiving lidocaine infusion would require less fentanyl in the PACU to achieve equivalent analgesic efficacy.

\section{Methods}

Patients

The study was approved by the McGill University Health Centre Ethics Board and was conducted between May 2007 and February 2008. Exclusion criteria were: age $<18 \mathrm{yr}$ or $>85 \mathrm{yr}$, ASA physical status III and greater, history of hepatic, renal or cardiac failure, organ transplant, diabetes, morbid obesity (body mass index $>40 \mathrm{~kg} \cdot \mathrm{m}^{-2}$ ), chronic use of opioids, allergy to local anesthetics, or inability to comprehend pain assessment. Patients were instructed before surgery in the use of the verbal rating scale (VRS) to assess pain and fatigue. They were also informed that they would receive a telephone call $24 \mathrm{hr}$ after the surgery, and would be asked to state their VRS at that time, as well as the amount of pain medication used. Before induction of anesthesia, the patients were randomly assigned, using a computer-generated randomization schedule, into two groups of 25 patients each: the control group received fentanyl $3 \mu \mathrm{g} \cdot \mathrm{kg}^{-1}$ iv at induction as the only intraoperative opioid, while the lidocaine group received fentanyl $1.5 \mu \mathrm{g} \cdot \mathrm{kg}^{-1}$ iv at induction and continuous intravenous infusion of lidocaine. Allocation concealment was achieved by placing the randomization sequence for each subject in sequentially numbered sealed brown envelopes.

\section{Anesthesia, analgesia and surgical care}

Upon arrival in the operating theatre, baseline values of heart rate, blood pressure, oxygen saturation and bispectral index (BIS) were recorded. The anesthetic technique was standardized, and the anesthesiologists (S.L. and F.C.) who executed the study protocol, were not involved in either the preoperative or the postoperative data collection. Patients were 
premedicated with midazolan $0.03 \mathrm{mg} \cdot \mathrm{kg}^{-1}$ iv. Before induction of anesthesia, patients in the control group received fentanyl $3.0 \mu \mathrm{g} \cdot \mathrm{kg}^{-1} i v$, while patients in the lidocaine group received fentanyl $1.5 \mu \mathrm{g} \cdot \mathrm{kg}^{-1}$ iv and a bolus injection of lidocaine $1.5 \mathrm{mg} \cdot \mathrm{kg}^{-1}$, followed by a continuous infusion of lidocaine $2 \mathrm{mg} \cdot \mathrm{kg}^{-1} \cdot \mathrm{hr}^{-1}$ until the end of surgery as previously reported. ${ }^{10} \mathrm{Gen}$ eral anesthesia was induced with propofol $2.5 \mathrm{mg} \cdot \mathrm{kg}^{-1}$ iv and endotracheal intubation was facilitated with rocuronium $0.8 \mathrm{mg} \cdot \mathrm{kg}^{-1} \mathrm{iv}$. Anesthesia was maintained with desflurane at an end-tidal concentration adjusted to maintain BIS values between 35 and 50, and the heart rate and systolic blood pressure within $\pm 20 \%$ of respective baseline values. No supplemental fentanyl was given to patients in either group during maintenance of anesthesia. The patients' lungs were mechanically ventilated with a mixture of air in oxygen $\left(\mathrm{F}_{\mathrm{I}} \mathrm{O}_{2} 40 \%\right)$, with minute ventilation adjusted to maintain normocarbia $\left(\mathrm{CO}_{2}\right.$ between 36 and $\left.44 \mathrm{mmHg}\right)$. Supplemental neuromuscular blockade was achieved with rocuronium $0.1 \mathrm{mg} \cdot \mathrm{kg}^{-1} i v$ following assessment of neuromuscular function with train-of-four monitoring. Intravenous normal saline $(0.9 \% \mathrm{NaCl})$ was administered during surgery at a rate of $6 \mathrm{~mL} \cdot \mathrm{kg}^{-1} \cdot \mathrm{hr}^{-1}$, and intraoperative normothermia was maintained with forced air warming blankets positioned over exposed parts of the body. Nasopharyngeal temperature was monitored throughout surgery. Soon after induction of anesthesia, acetaminophen $1.3 \mathrm{~g} p r$ was administered, and dexamethasone $8 \mathrm{mg}$ was given intravenously. Episodes of intraoperative hypotension (mean arterial blood pressure $<60 \mathrm{mmHg}$ ), and bradycardia (heart rate $<40$ beats. $\mathrm{min}^{-1}$ ) were recorded, and treated with intravenous boluses of neosynephrine 40 $\mu \mathrm{g}$ or atropine, $0.4 \mathrm{mg}$ respectively. Desflurane was discontinued after the last skin suture, and lidocaine infusion was also stopped at completion of surgery. Residual neuromuscular block was antagonized with neostigmine $0.05 \mathrm{mg} \cdot \mathrm{kg}^{-1}$ and glycopyrrolate 0.01 $\mathrm{mg} \cdot \mathrm{kg}^{-1} i v$. Ketorolac $15 \mathrm{mg}$ and droperidol 0.625 $\mathrm{mg}$ were also given intravenously. Patients were then transferred to the PACU.

All operations were performed by two surgeons who were highly experienced in laparoscopic cholecystectomy (L.F. and G.F.). After infiltration of 3 $\mathrm{mL}$ of $2 \%$ lidocaine in the infraumbilical region, open insertion of a blunt-tipped $12 \mathrm{~mm}$ trocar was used to access the peritoneal cavity. Pneumoperitoneum was achieved with carbon dioxide, and intra-abdominal pressure was maintained below $12 \mathrm{mmHg}$ throughout surgery. Three additional $5-\mathrm{mm}$ ports were introduced after infiltration of $2 \%$ lidocaine. All patients received a single dose of $5000 \mathrm{U}$ of heparin $s c$ and wore antiem- bolic stockings. Patients were positioned in a $30^{\circ}$ antiTrendelenburg position, and were rotated towards the left side to facilitate exposure of the gall bladder. At the end of surgery, patients were returned to a supine position, and residual carbon dioxide in the peritoneal cavity was expelled by abdominal compression. Ten millilitres of bupivacaine $0.25 \%$ with epinephrine was injected into the surgical incisions.

\section{Postoperative care and evaluations}

Patients were transferred to the PACU where the blood pressure, pulse, respiration and temperature were monitored and recorded by nurses who were blinded to the randomization sequence. According to study protocol, the PACU nursing staff administered fentanyl $25 \mu \mathrm{g} i v$ boluses for postoperative pain relief, to be administered every five minutes up to a maximum of $200 \mu \mathrm{g} \cdot \mathrm{hr}^{-1}$ only if the VRS score for pain $(0-10$ scale, where $0=$ no pain, and $10=$ excruciating pain) was $>3$, at rest. Ondansetron $2 \mathrm{mg} i v$ was prescribed for persistent nausea (lasting $>$ five minutes) or vomiting, and it could be repeated up to four times over a three-hour period if necessary. The anesthesia record was not made available to the recovery room nurse, to avoid bias. The nurses evaluated patients every five minutes or at the patient's request. Recovery status was evaluated on arrival in the recovery room, and every $30 \mathrm{~min}$ for the first two hours by two individuals (D.J.K. and G.M.) who were unaware of the randomization sequence, and having no interaction with either the nurses or the anesthesiologists.

The White-Song scoring system, previously validated for bypassing the PACU and transfer of patients directly from the operating room to the step-down unit, includes the following variables: level of consciousness, physical activity, hemodynamic stability, respiratory stability, oxygen saturation status, postoperative pain assessment and postoperative emetic symptoms. ${ }^{11}$ A minimal score of 12 of 14 points would be required for an outpatient to be fast-tracked after general anesthesia. In our institution, no step-down unit is available, and patients are discharged home directly from PACU. The time to achieve a WhiteSong score, of 12 of 14 points, was used as a tool to assess the speed of recovery.

Patients were discharged home by the nursing staff, according to the following institutionally-standardized criteria used for all outpatient surgeries: patient awake and oriented, stable hemodynamics, stable oxygen saturation $>95 \%$ on room air, minimal pain $(\mathrm{VRS}<4$ on ambulation), absence of nausea and vomiting, with an ability to tolerate oral fluids and to void, and to walk unaccompanied. Standardized rescue oral analgesics 
(acetaminophen $650 \mathrm{mg}$ every four hours, naproxen $500 \mathrm{mg}$ every $12 \mathrm{hr}$, and, if pain persisted, oxycodone $5 \mathrm{mg}$ every four hours, to be taken at home, were prescribed by the surgical team at discharge.

The following data were collected: demographic characteristics, duration of surgery and anesthesia, average end-tidal concentration of desflurane and BIS during surgery $(15,30,45$ and $60 \mathrm{~min}$ after induction of anesthesia); cumulative fentanyl dose and ondansetron administered in the PACU, time in the PACU until time discharged home, VRS, incidence of PONV, pruritus, urinary retention, and White-Song score. All patients were contacted by phone $24 \mathrm{hr}$ after discharge from hospital, to assess pain intensity (VRS) and presence of PONV at that time, and the amount of analgesics consumed in the first postoperative $24 \mathrm{hr}$.

\section{Statistical analysis}

The primary outcome of interest, the amount of fentanyl administered for postoperative pain relief to maintain visual analogue scale $<3$ in the PACU, was compared by Student's $t$ test. Secondary outcomes, including the incidence of persistent nausea and the use of ondansetron in the PACU, the White-Song score, and the time spent in the PACU before being discharged home were compared by Wilcoxon ranksum test. The latter were also applied to VRS scores, and for not normally distributed variables, while the Pearson $\chi^{2}$ test was used for categorical variables. Data are presented as mean \pm standard deviation (median) if normally distributed, and as median [interquartile range] if not, or absolute values (percentage). The level of significance was set at $P<0.05$ for all analyses. Statistical analysis was performed with the Intercooled Stata 9.2 statistical package (Stata Corporation, College Station, TX, USA).

Determination of sample size requirement was based on mean value of $168 \mu \mathrm{g} \pm$ standard deviation $95 \mathrm{\mu g}$ from a previous study ${ }^{12}$ from this institution on patients undergoing similar surgery. Twenty-five subjects in each group were required to detect a minimum of a $50 \%$ reduction in fentanyl requirement in the PACU, with a type-1 error of 0.05 and a power of $95 \%$.

\section{Results}

Sixty-three consecutive patients, scheduled for elective outpatient laparoscopic cholecystectomy, were invited to participate in this prospective, randomized study. Of the 63 patients who were screened, nine patients did not meet the criteria, while four patients refused participation. Fifty eligible patients were to be enrolled in this investigation. One patient in the control group
TABLE I Demographic characteristics and perioperative data

\begin{tabular}{|c|c|c|c|}
\hline & $\begin{array}{l}\text { Control } \\
n=25\end{array}$ & $\begin{array}{l}\text { Lidocaine } \\
n=25\end{array}$ & $P$ \\
\hline Male / female & $12 / 13$ & $5 / 20$ & \\
\hline Age (yr) & $53.8 \pm 16.4(54)$ & $50.2 \pm 15.5(51)$ & \\
\hline Weight (kg) & $75.0 \pm 14.8(72)$ & $66.9 \pm 13.8(68)$ & \\
\hline $\begin{array}{l}\text { Body mass } \\
\text { index }\left(\mathrm{kg} \cdot \mathrm{m}^{-2}\right)\end{array}$ & 25 [22.7-29.4] & $23.7[21.3-27.7]$ & \\
\hline ASA I/II & $11 / 14$ & $17 / 8$ & \\
\hline $\begin{array}{l}\text { History of } \\
\text { previous } \\
\text { PONV: } y / n\end{array}$ & $1 / 24$ & $0 / 25$ & \\
\hline $\begin{array}{l}\text { Amount of } \\
\text { intraoperative } \\
\text { fentanyl }(\mu \mathrm{g})\end{array}$ & $207.9 \pm 44.0(200)$ & $102.8 \pm 26.9(100)$ & $<0.0001$ \\
\hline $\begin{array}{l}\text { End-tidal } \\
\text { desflurane (\%) }\end{array}$ & $5.8 \pm 0.4(5.8)$ & $5.4 \pm 0.5(5.4)$ & 0.012 \\
\hline Bispectral index & $39.5 \pm 4.2(39.5)$ & $39.4 \pm 4.4(39.0)$ & 0.935 \\
\hline $\begin{array}{l}\text { Duration of } \\
\text { surgery (min) }\end{array}$ & $70[57.5-80]$ & $60[50-65]$ & 0.0158 \\
\hline $\begin{array}{l}\text { Converted to } \\
\text { open: } y / n\end{array}$ & $1 / 24$ & $0 / 25$ & 0.312 \\
\hline
\end{tabular}

Values are presented as absolute numbers, mean \pm standard deviation (median), or median [interquartile range]. $P$ values are calculated with Pearson $\chi^{2}$ test for categorical variables, Student's $t$ test for normally distributed variables and Wilcoxon rank-sum test for not-normally distributed variables. ASA = American Society of Anesthesiologists; PONV = postoperative nausea and vomiting.

was excluded from the analysis because his surgery was converted from laparoscopy to laparotomy. He received epidural analgesia with bupivacaine and fentanyl for 48 $\mathrm{hr}$ for postoperative analgesia and he was subsequently admitted to the surgical ward for three days.

Patient characteristics and intraoperative clinical data The study groups were similar with the exception of a greater proportion of males in the control group. The preoperative history of PONV, ASA status and intraoperative BIS scores were similar in the two groups. There was a reduction in the requirement of desflurane in the lidocaine group [Et desflurane 5.42\%, confidence interval (CI) $5.21-5.64 \%$ in the lidocaine group vs $5.77 \%$, CI $5.60-5.94 \%$ in the control group, $P=0.0123]$. The duration of surgery was longer in the control group by an average of ten minutes (68.83 $\mathrm{min}$, CI $60.54-77.13$ in the control group vs $55.64 \mathrm{~min}$ CI $50.43-60.85 \mathrm{~min}$ in the lidocaine group) (Table I). The mean dose of rocuronium (73 $\pm 17 \mathrm{mg}$ ) was similar in the two groups. Intraoperative complications (bronchospasm, bleeding) occurred in nine patients, with similar overall event frequencies in the two groups. During surgery, blood pressure and heart rate values were maintained within $\pm 20 \%$ of respective baseline values without requirement for either neosynephrine or atropine. Intraoperative body 
TABLE II Postoperative clinical data

\begin{tabular}{llll}
\hline & $\begin{array}{l}\text { Control } \\
n=24\end{array}$ & $\begin{array}{l}\text { Lidocaine } \\
n=25\end{array}$ & $P$ \\
\hline VRS 1 min & $4(2-5)$ & $5(3-6)$ & 0.436 \\
VRS 30 min & $4(2-5.5)$ & $4(3-5)$ & 0.723 \\
VRS 60 min & $3(2-4)$ & $3(2-4)$ & 0.534 \\
VRS 90 min & $3(1-3)$ & $3(2-4)$ & 0.488 \\
& & & \\
White-Song score 1 min & $11(10-12)$ & $11(10-12)$ & 0.563 \\
White-Song score 30 min & $13(11-14)$ & $13(12-14)$ & 0.624 \\
White-Song score 60 min & $14(13-14)$ & $14(13-14)$ & 0.488 \\
White-Song score 90 min & $14(13-14)$ & $14(13-14)$ & 0.341 \\
\hline
\end{tabular}

Values are presented as median (interquartile range). $P$ values are calculated with Wilcoxon rank-sum test. VRS = verbal rating scale for pain.

temperatures were maintained between 35.7 and $37.3^{\circ} \mathrm{C}$, with no difference between groups.

\section{Postoperative clinical data}

Three patients (two in the control group, and one patient in the lidocaine group) were admitted by the surgical team for overnight observation: one patient for bleeding, another for persistent hypertension, and a third for rapid atrial fibrillation. All three patients were discharged the following day. Verbal rating scale scores for pain at rest, and the White-Song scores at admission to PACU and every $30 \mathrm{~min}$ for the first 90 min were similar in the two groups (Table II). Most patients received fentanyl for pain relief in the PACU, but the cumulative amount was lower in the lidocaine group (153.54 $\mu \mathrm{g}$, CI 111.53-195.55 $\mu \mathrm{g}$ ) compared to the control group $(98.00 \mu \mathrm{g}$, CI 75.52-120.48 $\mu \mathrm{g}$ ) (Table III). The overall frequency of persistent nausea requiring ondansetron in the control group was similar to that of the lidocaine group. One patient in the control group experienced urinary retention. Patients in both groups reached the White-Song score above 12 by $30 \mathrm{~min}$ from the time they were admitted to the PACU, and there was no difference in the time interval between arrival to the PACU and discharge home.

The VRS scores for pain and fatigue and the incidence of PONV in the first 24 postoperative hours were similar in the two groups (Table IV). The average amount of acetaminophen, naproxen and oxycodone consumed in the first 24 postoperative hours was similar in both groups.

\section{Discussion}

The results of this study indicate that, in presence of low dose intraoperative opioid, an intravenous infusion of lidocaine impacts on postoperative analge-
TABLE III Treatment in the PACU and assessment of recovery

\begin{tabular}{llll}
\hline & $\begin{array}{l}\text { Control } \\
n=24\end{array}$ & $\begin{array}{l}\text { Lidocaine } \\
n=25\end{array}$ & $P$ \\
\hline $\begin{array}{l}\text { Amount of } \\
\text { fentanyl used }(\mu \mathrm{g})\end{array}$ & $\begin{array}{l}153.5 \pm 99.5 \\
(162.5)\end{array}$ & $98.0 \pm 54.4(100) 0.018$ \\
$\begin{array}{l}\text { Persistent nausea in } \\
\text { recovery room: } n(\%)\end{array}$ & $8(33)$ & $4(16)$ & 0.087 \\
$\begin{array}{l}\text { Use of } \\
\text { ondansetron: }\end{array}$ & $8(33)$ & $4(16)$ & 0.087 \\
$\begin{array}{l}n \%) \\
\text { No. of patients }\end{array}$ & $16 / 0 / 6 / 2$ & $21 / 2 / 1 / 1$ & 0.158 \\
$\begin{array}{l}\text { requiring ondansetron } \\
(0 / 2 / 4 / 8 \text { mg) }\end{array}$ & & & \\
$\begin{array}{l}\text { No. of patients with } \\
\text { White-Song score }>\end{array}$ & $10 / 6 / 8$ & $11 / 11 / 3$ & 0.152 \\
$\begin{array}{l}12 \text { at } 1^{\text {st }} / 30^{\text {th }} / 60^{\text {th }} \\
\text { min or more }\end{array}$ & & & \\
$\begin{array}{l}\text { Time from arrival to } \\
\text { PACU to discharge } \\
\text { home (min) }\end{array}$ & $167.5[132-225] 180[155-220]$ & 0.649 \\
\hline
\end{tabular}

Values are presented as median (interquartile range), absolute number, or mean \pm standard deviation (median). $P$ values are calculated with Student's $t$ test for the parametric normally distributed variables, Pearson $\chi^{2}$ test for categorical variables, Wilcoxon rank-sum test for the parametric not-normally distributed variables. $\mathrm{PACU}=$ postanesthesia care unit.

sia by decreasing the postoperative requirements of fentanyl.

Intravenous lidocaine has been shown to be analgesic, anti-hyperalgesic and anti-inflammatory. Animal experiments and clinical studies have revealed the antinociceptive effects of intravenous sodium channel blockers. The effect is thought to reflect the inhibition of primary evoked polysynaptic reflexes in the spinal dorsal horn mediated by a variety of mechanisms including sodium channel blockade. ${ }^{13}$ In addition, lidocaine has been shown to have anti-inflammatory properties with modulation of excessive inflammatory response. ${ }^{14}$ Perioperative intravenous lidocaine decreases postoperative pain and morphine consumption following prostatic surgery ${ }^{5}$ and colon resection. ${ }^{10}$ Pain scores improve more during activity than at rest in patients enrolled in an acute rehabilitation program. ${ }^{10}$ In addition, restoration of gut motility is facilitated and length of hospital stay is shortened..$^{15} \mathrm{~A}$ possible anti-inflammatory mechanism for accelerating bowel function has been proposed, and more specifically lidocaine seems to target different steps within the inflammatory cascade, the increase in complement and pro-inflammatory cytokines. ${ }^{14,15}$ The latter have been shown to be responsible for maintaining postoperative ileus and intestinal permeability disorders. ${ }^{15}$ Postoperative pain after laparoscopic cholecystectomy 
TABLE IV Clinical assessment and medications used during the first postoperative $24 \mathrm{hr}$

\begin{tabular}{llll}
\hline & $\begin{array}{l}\text { Control } \\
n=24\end{array}$ & $\begin{array}{l}\text { Lidocaine } \\
n=25\end{array}$ & $P$ \\
\hline VRS pain at rest & $2(1-3)$ & $1.5(0-2)$ & 0.149 \\
VRS pain on coughing & $4(2-5)$ & $2.5(2-4)$ & 0.223 \\
VRS pain on walking & $2(1-3)$ & $2(1-3)$ & 0.943 \\
VRS shoulder pain & $0(0-2)$ & $0(0-1)$ & 0.445 \\
VRS fatigue & $3(2-5)$ & $3(2-4)$ & 0.389 \\
PONV y/n & $4 / 18$ & $2 / 20$ & 0.380 \\
Acetaminophen $(\mathrm{mg})$ & $1614 \pm 1252$ & $1393 \pm 1404$ & 0.585 \\
& $(1400)$ & $(1000)$ & \\
Naproxen (mg) & $682 \pm 547$ & $704 \pm 454$ & 0.882 \\
& $(1000)$ & $(1000)$ & \\
Oxycodone $(\mathrm{mg})$ & $7.7 \pm 11.0(5)$ & $9.1 \pm 8.1(10)$ & 0.642 \\
\hline
\end{tabular}

Values are presented as median (interquartile range), or absolute numbers. $P$ values are calculated with Pearson $\chi^{2}$ test for categorical variables, and Wilcoxon rank-sum test for parametric not-normally distributed variables. VRS = verbal rating scale for pain; $\mathrm{PONV}=$ postoperative nausea and vomiting.

include not only incisional pain, but also visceral pain arising from damage to internal organs. ${ }^{3}$ While pain was reported as the dominant complaint and the primary reason for postoperative admission after laparoscopic cholecystectomy, ${ }^{4}$ the implementation of multimodal analgesia during the last decade has made this operation an ambulatory procedure in the majority of patients.

There has been some interest in providing guidelines with regards to the surgical and anesthetic management of laparoscopic cholecystectomy following the realization that patients' outcomes can still be significantly improved. ${ }^{16}$ This requires a revision of the role of the perioperative care team from providing not only adequate analgesia, but to rearranging the overall perioperative care. A step-up approach has been recommended on the basis of procedurespecific evidence, from data related to other procedures and from meta-analyses. ${ }^{17}$ This includes several modalities aimed at minimizing the metabolic stress, enhancing the anti-inflammatory response and maximizing perioperative analgesia. In the present study, the recommendations proposed by the Procedure Specific Postoperative Pain Management (PROSPECT) group were followed, with specific attention to: maintaining normothermia, minimizing tissue damage by using small trocars, preventing PONV, administering adequate fluid intake, and insufflating the peritoneum with low-pressure $\mathrm{CO}_{2}$. In addition, multimodal analgesic interventions such as local anesthetics infiltration in the surgical incision, short-acting opioids and adequate doses of anti-inflammatory agents and acetaminophen were provided. ${ }^{17}$ Within the context of an integrated approach, attempts have been recently made to introduce adjuvants with the intention to facilitate early recovery ${ }^{18}$ and to decrease the side effects related to opioids. ${ }^{1}$ Esmolol, an ultrashort-acting cardioselective $\beta 1$ - adrenergic receptor antagonist has been infused during laparoscopic cholecystectomy by this group as an alternative to the intraoperative use of fentanyl. ${ }^{12}$ It was found to provide a significant postoperative opioid-sparing effect with less PONV and faster hospital discharge. In the present study, the average amount of postoperative fentanyl administered in the lidocaine group was similar to that reported in the esmolol study, indicating that a similar opioid-sparing effect can be achieved with a simple and inexpensive drug such as lidocaine. However, the improved analgesia was not sufficient to attenuate the incidence of persistent nausea in the PACU and to facilitate hospital discharge. One possible explanation is that the study was not powered to detect statistical differences in this secondary outcome. Secondly, the intraoperative dose of fentanyl in the lidocaine group, (half of that administered to the control group), might have been sufficient to have induced persistent nausea, triggering the use of ondansetron, thus delaying the time for home discharge. Whether lidocaine infusion in the absence of intraoperative opioids would spare the amount of postoperative fentanyl required, and further decrease the incidence of persistent nausea, warrants evaluation in future studies examining the predictive risk of PONV.

All investigations conducted with lidocaine infusions, to date, included concurrent intraoperative opioid administration, although in the present study the dose of fentanyl was deliberately reduced by half to test for intraoperative opioid sparing. In addition to opioid sparing during surgery, with lidocaine infusion, there was a $10 \%$ reduction in the amount of desflurane required to maintain hemodynamic stability and BIS during surgery. This observation is in agreement with other studies ${ }^{10,12,19,20}$ which report a reduction in the concentration of inhalational agents with concurrent infusion of lidocaine.

No differences in self-reported pain scores and PONV were observed between the two groups 24 hr after surgery, as has been shown in a previous laparoscopic cholecystectomy study. ${ }^{9}$ In addition, these same authors could not demonstrate any effect of lidocaine on restoration of bowel function. This observation might have been due to the short period of lidocaine infusion necessary to attenuate the inflammatory response, by promoting leukocyte inhibition 
and subsequent activation of an inhibitory adrenergic pathyway. ${ }^{14}$ In fact, when lidocaine infusion was continued for $24 \mathrm{hr}$ in the postoperative period, the duration of ileus after colon resection was shortened with better postoperative analgesia. ${ }^{10}$ Recently, intravenous lidocaine was used for total hip arthroplasty, and no impact on postoperative analgesia was reported. ${ }^{21}$ This finding lends further support to the predominant role of lidocaine in the treatment of visceral pain.

In conclusion, intraoperative lidocaine infusion, in combination with low intraoperative doses of short-acting opioids reduces the consumption of fentanyl in the PACU, and the intraoperative desflurane requirements. There is a need to address, in future investigations, whether or not lidocaine impacts on postoperative nausea and vomiting.

\section{References}

1 White PF. The role of non-opioid analgesic techniques in the management of pain after ambulatory surgery. Anesth Analg 2002; 94: 577-85.

2 Watt-Watson J, Chung F, Chan VW, McGillion M. Pain management following discharge after ambulatory same-day surgery. J Nurs Manag 2004; 12: 153-61.

3 Bisgaard T, Klarskov B, Rosenberg J, Keblet $H$. Characteristics and prediction of early pain after laparoscopic cholecystectomy. Pain 2001; 90: 261-9.

4 Bisgaard T. Analgesic treatment after laparoscopic cholecystectomy: a critical assessment of the evidence. Anesthesiology 2006; 104: 835-46.

5 Groudine SB, Fisher HA, Kaufman RP Jr, et al. Intravenous lidocaine speeds the return of bowel function, decreases postoperative pain, and shortens hospital stay in patients undergoing radical retropubic prostatectomy. Anesth Analg 1998; 86: 235-9.

6 Koppert W, Weigand M, Neumann F, et al. Perioperative intravenous lidocaine has preventive effects on postoperative pain and morphine consumption after major abdominal surgery. Anesth Analg 2004; 98: 1050-5.

7 Ness TJ. Intravenous lidocaine inhibits visceral nociceptive reflexes and spinal neurons in the rat. Anesthesiology 2000; 92: 1685-91.

8 Hollmann MW, Durieux ME. Local anesthetics and the inflammatory response: a new therapeutic indication? Anesthesiology 2000; 93: 858-75.

$9 W u$ CT, Borel CO, Lee MS, et al. The interaction effect of perioperative cotreatment with dextromethorphan and intravenous lidocaine on pain relief and recovery of bowel function after laparoscopic cholecystectomy. Anesth Analg 2005; 100: 448-53.

10 Kaba A, Laurent SR, Detroz BJ, et al. Intravenous lidocaine infusion facilitates acute rehabilitation after laparoscopic colectomy. Anesthesiology 2007; 106: 11-8; discussion 5-6.

11 White PF, Song D. New criteria for fast-tracking after outpatient anesthesia: a comparison with the modified Aldrete's scoring system. Anesth Analg 1999; 88: 1069-72.

12 Collard V, Mistraletti G, Taqi A, et al. Intraoperative esmolol infusion in the absence of opioids spares postoperative fentanyl in patients undergoing ambulatory laparoscopic cholecystectomy. Anesth Analg 2007; 105: 1255-62.

13 Pypendop BH, Ilkiw JE. The effects of intravenous lidocaine administration on the minimum alveolar concentration of isoflurane in cats. Anesth Analg 2005; 100: 97-101.

14 Hollmann $M W$, Gross A, Jelacin N, Durieux ME. Local anesthetic effects on priming and activation of human neutrophils. Anesthesiology 2001; 95: 113-22.

15 Herroeder S, Pecher S, Schonherr ME, et al. Systemic lidocaine shortens length of hospital stay after colorectal surgery: a double-blinded, randomized, placebo-controlled trial. Ann Surg 2007; 246: 192200.

16 Lau H, Brooks DC. Contemporary outcomes of ambulatory laparoscopic cholecystectomy in a major teaching hospital. World J Surg 2002; 26: 1117-21.

17 Kehlet H, Gray AW, Bonnet F, et al. A procedurespecific systematic review and consensus recommendations for postoperative analgesia following laparoscopic cholecystectomy. Surg Endosc 2005; 19: 1396-415.

18 Song D, White PF. Remifentanil as an adjuvant during desflurane anesthesia facilitates early recovery after ambulatory surgery. J Clin Anesth 1999; 11: 364-7.

19 Himes RS Jr, DiFazio CA, Burney RG. Effects of lidocaine on the anesthetic requirements for nitrous oxide and halothane. Anesthesiology 1977; 47: 437-40.

20 Hollmann MW, Strumper D, Herroeder S, Durieux $M E$. Receptors, G proteins, and their interactions. Anesthesiology 2005; 103: 1066-78.

21 Martin F, Cherif K, Gentili ME, et al. Lack of impact of intravenous lidocaine on analgesia, functional recovery, and nociceptive pain threshold after total hip arthroplasty. Anesthesiology 2008; 109: 118-23. 